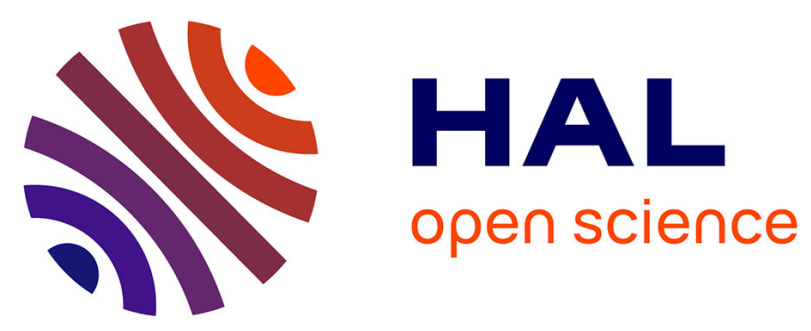

\title{
On Nonlinear Robust Adaptative Control: Application on Electro-Hydraulic Valve System
}

Lilia Sidhom, Inès Chihi, Xavier Brun, Eric Bideaux, Daniel Thomasset

\section{To cite this version:}

Lilia Sidhom, Inès Chihi, Xavier Brun, Eric Bideaux, Daniel Thomasset. On Nonlinear Robust Adaptative Control: Application on Electro-Hydraulic Valve System. Sundarapandian Vaidyanathan; Christos Volos. Advances and Applications in Nonlinear Control Systems, 635, Springer, pp.575594, 2016, Studies in Computational Intelligence, 978-3-319-30169-3. 10.1007/978-3-319-30169-3_25 . hal-01873427

\section{HAL Id: hal-01873427 https://hal.science/hal-01873427}

Submitted on 2 Apr 2019

HAL is a multi-disciplinary open access archive for the deposit and dissemination of scientific research documents, whether they are published or not. The documents may come from teaching and research institutions in France or abroad, or from public or private research centers.
L'archive ouverte pluridisciplinaire HAL, est destinée au dépôt et à la diffusion de documents scientifiques de niveau recherche, publiés ou non, émanant des établissements d'enseignement et de recherche français ou étrangers, des laboratoires publics ou privés. 


\title{
On Nonlinear Robust Adaptative Control: Application on Electro-hydraulic Valve System
}

\author{
Lilia Sidhom ${ }^{1}$, Ines Chihi ${ }^{2}$, Xavier. Brun ${ }^{3}$, Eric Bideaux ${ }^{4}$, \\ Daniel Thomasset ${ }^{5}$ \\ ${ }^{1,2}$ LARA Laboratory ENIT, Tunis , Tunisa \\ 3,4,5 AMPERE Laboratory UMR CNRS 5005, INSA-Lyon, France \\ \{lilia.sidhom@gmail.com\}
}

\begin{abstract}
In this work, a robust adaptive control (RAC) of electro-hydraulic servo-system is investigated. The dynamics of hydraulic systems are highly nonlinear and the system may be subjected to some discontinuous nonlinearity due principally to servo-valve characteristics. Aside from the nonlinear nature of hydraulic dynamics, our test bench presents an intermediate interface between the actuator and the servo-valve, which leads to have some pressure drop between the servo-valve and the cylinder chambers. This pressure drop depends on some operating conditions. Therefore, the system may possess both parametric uncertainties and unknown nonlinear functions that may represent modelling errors. To address these challenging issues, the robust adaptive control (RAC) is applied. Based on adaptive update techniques, the parametric uncertainties are compensated. Moreover, a robust method is used to solve the problem derived from the modelling errors. The proposed controller ensure that the position tracking errors of the system remains bounded and can be made arbitrarily small. Simulation studies on the control of hydraulic servo-actuator show the effectiveness of the proposed scheme.
\end{abstract}

Keywords: electro-hydraulic system, nonlinear system, uncertainties model, adaptive control, Lyapunov method, robust control.

\section{Introduction}

Hydraulic actuators are widely utilized in industry, ranging from heavy-duty applications such as hydraulic manipulators to precision machine tool control and ground base simulators. Moreover, the compactness, the high force-to-mass ratio and the reliable performance of hydraulic actuators are factors that could potentially be exploited in sophisticated manipulator design. However, the dynamic behaviour of hydraulic systems is highly nonlinear. These nonlinearities depend on the servo-valve flow-pressure characteristics, change of the control volumes and 
the friction force equation [1]. Furthermore, the electro-hydraulic system has many uncertainties models, which are generated by both parametric uncertainties and uncertain nonlinearities. Parametric uncertainties consist to the large variations in the hydraulic parameters, due generally to the change of the operating conditions such as oil temperature and supply pressure. The other uncertainties include uncertain dynamics such as leakage flow, dry friction which can be described by some unknown functions.

The complexity of the electro-hydraulic systems and the important range of control laws are a real industrial problem where the target is to choose the best control strategy for an application. For this reason, some research efforts have been directed toward meeting this requirement. Most of them have been based on the linear control theory [2], [3]. But in such works, some important dynamic information may be lost when the hydraulic servo system is linearized around some operating point, during the design.

Therefore, it is important to choose a nonlinear control method that is reasonably suitable for hydraulic servo systems. Some numbers of investigations have been conducted on feedback linearization techniques [4], [5], [6]. But these methods did not account for model uncertainties and also require exact knowledge of the system dynamics. To overcome this problem, nonlinear robust control techniques are essentially used for controlling this kind of systems with a good performance. In this way, a sliding mode variable structure controller is adopted in electro-hydraulic systems in some research works [7], [8] and [9]. A specific drawback associated with implementation of such technique is the chattering phenomenon, which is essentially a high frequency switching of the control. In effect, the presence of a discontinuous function in a controller design can affected the performance of the controlled system [10].

For an electro-hydraulic system, the adaptive control is considered as one valid method that can maintain consistent performances in the presence of some variations in plant parameters. There exists relatively little general theory for the adaptive control of nonlinear systems. In the previous research, some kinds of nonlinear robust adaptive control (RAC) laws have been investigated and applied for some application. For example, a feedback linearization adaptive control [6] and a nonlinear robust adaptive control based on backstepping technique are employed on [11], [12], [13]. In these latter works, the backstepping design procedures [14] are presented in order to design a global stable controller for a class of nonlinear systems transformable to a strict-feedback form. Some alternative approach is based on both sliding mode and an adaptive technique, which is defined by the integral-type adaptation law, [15]. In [16], the authors applied nonlinear RAC in single-rod cylinder hydraulic system based on backstepping technique to compensate the uncertainties. A systematic design procedure to combine the adaptive control and the smoothed sliding mode control for tracking objectives of robot manipulators is presented in [17], where the control designer is described for a multiinput multi-output (MIMO) nonlinear system. In [18], [19] the authors consider that the original total control volumes are uncertain unknown nonlinear parameters. This kind of consideration can be useful when the dynamic system is affected by a small variation of the original control volumes. 
In this work, we address the RAC of electro-hydraulic system with nonlinear and parametric uncertainties. The major contribution of this work concerns the effectiveness of the controller design on the real system. This system is a symmetric double acting electro-hydraulic servo-drive is considered. This system disposes of some interface block between the actuator and the servo-valve. The presence of this interface generates some pressure drop between the servo-valve and the cylinder chambers. This derived pressure decrease depends on the geometrical characteristics of the different pipes constituting this block, the velocity of the fluid and also the input exciting signal. In order to obtain a good performance, with presence of an intermediary interface, a RAC is applied. Effectively, this kind of technique can successfully solve the control problem, particularly in the presence of unknown parameters. Such control law gives an idea about the evolution of some unknown parameters, for example the value of the pressure drop caused by the intermediate block, in each operating conditions.

The RAC of single-input single-output (SISO) nonlinear system in a strictfeedback form is considered with allowing both parametric uncertainties and unknown nonlinear functions, with assuming a prior knowledge of some bounds. By introducing the projection technique to the integral-type adaptation law and based on the Lyapunov method, a simpler control law and adaptive mechanism are designed. We combine a defined adaptive controller with a conventional robust control method to obtain a RAC.

The outline of the work is as follows. In Section 2, the detailed nonlinear model is presented. In Section 3, the designed robust adaptive control for the electrohydraulic system is given. The following section is dedicated to the simulation results and discussion.

\section{Electro-hydraulic servo-system model First Heading}

Table 1 illustrates descriptions and units of several parameters used in this work.

Table 1. List of notation

\begin{tabular}{ccc}
\hline Parameter & Description & Unit \\
\hline $\mathrm{b}$ & viscous friction coefficient & $\mathrm{N} / \mathrm{m} / \mathrm{s}$ \\
$\mathrm{M}$ & total load mass & $\mathrm{kg}$ \\
$\mathrm{p}$ & pressure in the cylinder chamber & $\mathrm{Pa}$ \\
$\mathrm{S}$ & area of the piston cylinder & $\mathrm{m} 2$ \\
$\mathrm{~V}$ & volume & $\mathrm{m} 3$ \\
$\mathrm{y}, \mathrm{v}, \mathrm{a}$ & Position, velocity, acceleration & $\mathrm{m}, \mathrm{m} / \mathrm{s}, \mathrm{m} / \mathrm{s} 2$ \\
$\rho$ & fluid density & $\mathrm{kg} / \mathrm{m} 3$ \\
$h(t)$ & Dry friction function & $\mathrm{N}$ \\
1 & length of stroke & $\mathrm{m}$ \\
$x_{t}$ & Spool valve displacement & $\mathrm{m}$ \\
$\phi$ & pressure drop caused by the intermediary interface & $\mathrm{Pa}$
\end{tabular}


The considered system Fig. 1 is a symmetric double acting electro-hydraulic servo-drive using a double-rod cylinder with a stroke of $330 \mathrm{~mm}$, controlled by a five two-way servo-valve.

The intermediary interface is specifically produced for our test bench to implement two servo-valves in order to ensure different operating mode of the system. However the presence of this block, let to have output flow of servo-valve $\left(Q_{11}, Q_{12}\right)$ is different than the input flow of the actuator $\left(Q_{1}, Q_{2}\right)$, see Fig.1.

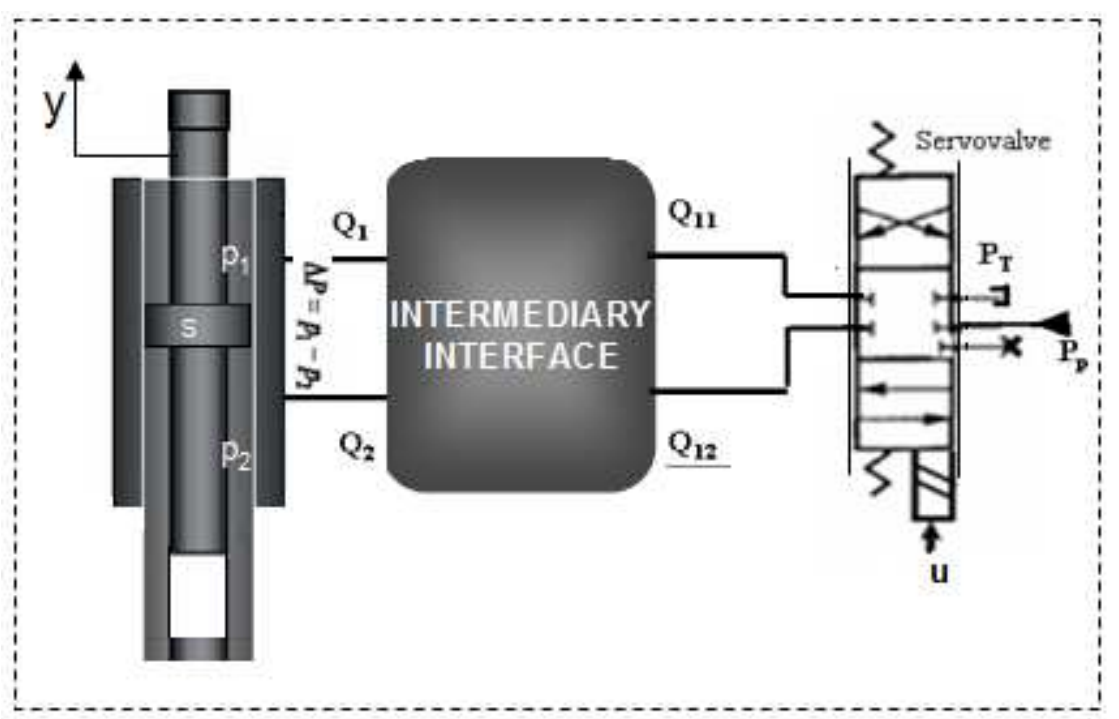

Fig. 1: Schematic diagram of the studied hydraulic system

In this work, the intermediate block is just approximated to a resistive component which is described by some pipes. The simulation model of the system is designed on the AMESim software, by the Fig.2. This model introduces some components which are neglected on the control model. The added components in the simulation model include two pipes between the cylinder chambers and the servovalve in order to represent the intermediary block in a simplified way, two accumulators, and some lines respectively on the supply and exhaust pressure way. In this model, the dynamic of the servovalve is described by a second-order model. The pulsation of this model is fixed in order to be higher than the actuator. The viscous, stiction and coulomb friction forces are taken into account in this model.

As a first step, the control law defined in this work is designed by a more simplified model denoted by control model. The used equations of the control model are explained as below. The dynamic of the inertia load is: 


$$
M a=S \Delta P-M g-b v-h(t) .
$$

where $M$ is the mass of the moving part, $\Delta P=p_{1}-p_{2}$ is the drop across load piston, $S$ is the effective area of the two chambers, $b$ represents the coefficient of the viscous friction force, $v, a$ are respectively the velocity and the acceleration of the load. Dry friction force is represented by the function $h(t)$. This function must be a nonlinear and a differentiable one with bounded value. For this reason, the dry friction force is defined around null velocity by a smooth function such as a "tanh" instead of the "sign" function.

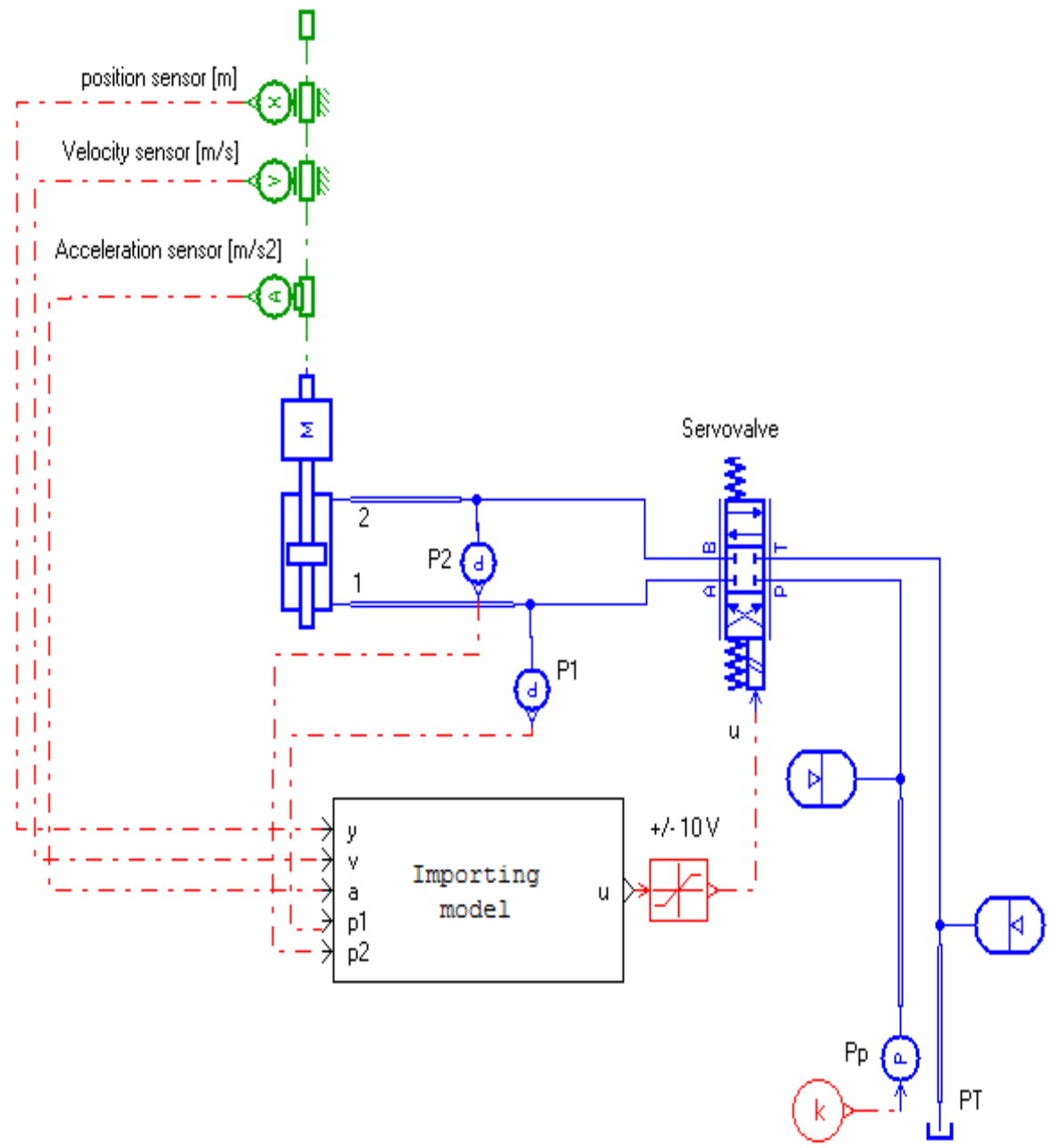

Fig.2: Simulation model of the studied system 
The governing nonlinear equations that describe the fluid flow distribution in the valve can be written in their simplest forms [1]:

$$
\left\{\begin{array}{l}
Q_{1}=\frac{V_{1}(y)}{\beta} \frac{d p_{1}}{d t}+\frac{d V_{1}}{d t} \\
Q_{2}=\frac{V_{2}(y)}{\beta} \frac{d p_{2}}{d t}+\frac{d V_{2}}{d t}
\end{array}\right.
$$

Where $\beta$ is the effective bulk modulus, $V_{1}$ and $V_{2}$ are the total volumes of the cylinder, defined respectively by $V_{1}(y)=V_{0}+S y$ and $V_{2}(y)=V_{0}-S y$, with: $V_{0}=V_{D}+S \frac{l}{2}$ is the piping volume of the chambers for the zero position, $V_{D}$ is a dead volume present on each extremities of the cylinder, $y$ is the displacement of the load and $l$ is the cylinder stroke. With D notes a subscript of the dead volume in the cylinder chamber, $\mathrm{S}$ and $\mathrm{T}$ are respectively a subscript denote a supply and an exhaust pressure.

In this present work, some assumptions are considered. Firstly consider that the spool valve displacement $x$ is related to the control voltage $u$ by a given equation: $x_{t}=K_{s v} u$. This type of assumption can be used in control [19] for some operating mode.

The flow laws can be written as follows:

$$
\left\{\begin{array}{l}
Q_{1}=\eta \cdot \psi_{1}\left(p_{1}, p_{P}, p_{T}, \operatorname{sign}(u)\right) u \\
Q_{2}=-\eta . \psi_{2}\left(p_{2}, p_{P}, p_{T}, \operatorname{sign}(u)\right) u
\end{array}\right.
$$

where:

$$
\left\{\begin{aligned}
\psi_{1}\left(\mathrm{p}_{1}, \mathrm{p}_{\mathrm{p}}, \mathrm{p}_{\mathrm{T}}, \operatorname{sign}(\mathrm{u})\right) & =\alpha\left[\gamma(\mathrm{u}) \sqrt{\left|\mathrm{p}_{\mathrm{P}}-\mathrm{p}_{1}\right|} \operatorname{sign}\left(\mathrm{p}_{\mathrm{P}}-\mathrm{p}_{1}\right)\right. \\
+ & \left.\gamma(-\mathrm{u}) \sqrt{\left|\mathrm{p}_{1}-\mathrm{p}_{\mathrm{T}}\right|} \operatorname{sign}\left(\mathrm{p}_{1}-\mathrm{p}_{\mathrm{T}}\right)\right] \\
\psi_{2}\left(\mathrm{p}_{2}, \mathrm{p}_{\mathrm{p}}, \mathrm{p}_{\mathrm{T}}, \operatorname{sign}(\mathrm{u})\right) & =\left[\alpha \gamma(\mathrm{u}) \sqrt{\left|\mathrm{p}_{2}-\mathrm{p}_{\mathrm{T}}\right|} \operatorname{sign}\left(\mathrm{p}_{2}-\mathrm{p}_{\mathrm{T}}\right)\right. \\
+ & \left.\gamma(-\mathrm{u}) \sqrt{\left|\mathrm{p}_{\mathrm{P}}-\mathrm{p}_{2}\right|} \operatorname{sign}\left(\mathrm{p}_{\mathrm{P}}-\mathrm{p}_{2}\right)\right]
\end{aligned}\right.
$$

with: $\gamma(\mathrm{u})=\frac{1+\operatorname{sign}(\mathrm{u})}{2}$ and the function $\operatorname{sign}(\mathrm{u})$ is defined by: 


$$
\operatorname{sign}(u)=\left\{\begin{array}{rr}
1 & u \geq 0 \\
-1 & u<0
\end{array}\right.
$$

$p_{P}, p_{T}$ are respectively the supply pressure and the exhaust pressure of the fluid. The servo-valve is supposed a symmetric one, which justify the presence of the same variable gain $\eta$ in the two flow laws. The flow gain $\eta$ is defined by a given expression $\eta=C_{q} \omega \phi, C_{q}$ is the flow coefficient of each restriction, $\omega$ is the spool valve area gradient, and $\phi$ is the pressure drop caused by the intermediary interface. Let us define the known variable $\alpha$ by $\alpha=K_{s v} \sqrt{\frac{2}{\rho}}$, where $\rho$ is a fluid density.

Note that under normal practical working condition, the domain of the pressure is defined by:

$$
\left.p_{1}, p_{2} \in \Omega_{p} \triangleq\right] p_{T}, p_{P}[
$$

with the assumption (5), the term $\operatorname{sign}\left(p_{P}-p_{j}\right)$ and $\operatorname{sign}\left(p_{j}-p_{T}\right)$ introduced in (4) can be deleted, with $j=\{1,2\}$.

Define the state variable $X=[\mathrm{y}, \mathrm{v}, \mathrm{a}]^{\mathrm{T}}$. The system can be expressed in state space form as:

$$
\left\{\begin{aligned}
\dot{\mathrm{y}} & =\mathrm{v}, \\
\dot{\mathrm{v}} & =\mathrm{a}, \\
\dot{\mathrm{a}} & =\frac{\beta . S}{\mathrm{M}\left(\mathrm{V}_{0}+\mathrm{Sy}\right)}\left(\eta \psi_{1}\left(\mathrm{p}_{1}, \mathrm{p}_{\mathrm{p}}, \mathrm{p}_{\mathrm{T}}, \operatorname{sign}(\mathrm{u})\right) \mathrm{u}-\mathrm{Sv}\right) \\
& -\frac{\mathrm{S} . \beta}{\mathrm{M}\left(\mathrm{V}_{0}-\mathrm{Sy}\right)}\left(-\eta \psi_{2}\left(\mathrm{p}_{2}, \mathrm{p}_{\mathrm{p}}, \mathrm{p}_{\mathrm{T}}, \operatorname{sign}(\mathrm{u})\right) \mathrm{u}+\mathrm{Sv}\right)-\frac{\mathrm{b}}{\mathrm{M}} \mathrm{a}-\frac{\dot{\mathrm{h}}(\mathrm{t})}{\mathrm{M}} .
\end{aligned}\right.
$$

Given the desired trajectories $\mathrm{y}_{\mathrm{d}}, \mathrm{v}_{\mathrm{d}}, \mathrm{a}_{\mathrm{d}}$ our work aims to synthesize a control input $\mathrm{u}$ such that the position tracking error of the system remains as closely as possible to zero in spite of various model uncertainties.

The desired trajectories are assumed to be all bounded and $y_{d}$ must be chosen in order to respect the required differentiability. 


\section{Controller Design}

The system is subjected to parametric uncertainties due to the variations of $b, \omega, C_{q}, \phi$ and $\beta$ in the work process for different environments conditions, as the influence of bulk modulus due to entrapped air or temperature. In this work, the parametric uncertainties of important parameters $\beta, b$ and the coefficient flow gain $\eta$ are taken into account. Moreover $S, M, V_{0}$ are considered as fixed and known parameters.

In this section we describe one class of SISO system to design a RAC for the considered nonlinear system. From the system (6), some conditions can be satisfied such that the nonlinear plant dynamics shall be linearly parameterized [19] and we suppose that the full state is measurable.

Let $\mathrm{c}=\frac{\mathrm{V}_{0}}{\mathrm{~S}}$, so the third equation of the system (6) can be rewritten:

$$
\begin{aligned}
\dot{\mathrm{a}} & =\frac{1}{(\mathrm{c}+\mathrm{y})(\mathrm{c}-\mathrm{y})}\left[(\mathrm{c}-\mathrm{y})\left(\frac{\beta}{\mathrm{M}} \eta \psi_{1}\left(\mathrm{p}_{1}, \mathrm{p}_{\mathrm{p}}, \mathrm{p}_{\mathrm{T}}, \operatorname{sign}(\mathrm{u})\right) \mathrm{u}-\frac{\beta}{\mathrm{M}} \mathrm{Sv}\right)\right. \\
& \left.-(\mathrm{c}+\mathrm{y})\left(-\frac{\beta}{\mathrm{M}} \eta \psi_{2}\left(\mathrm{p}_{2}, \mathrm{p}_{\mathrm{p}}, \mathrm{p}_{\mathrm{T}}, \operatorname{sign}(\mathrm{u})\right) \mathrm{u}+\frac{\beta}{\mathrm{M}} \mathrm{Sv}\right)\right]-\frac{\mathrm{b}}{\mathrm{M}} \mathrm{a}-\frac{\dot{\mathrm{h}}(\mathrm{t})}{\mathrm{M}}
\end{aligned}
$$

The above equation can be transformed in terms of unknown parameters $\theta_{i}$ as:

$$
\begin{aligned}
& \dot{\mathrm{a}=} \frac{1}{\left(\mathrm{c}^{2}-\mathrm{y}^{2}\right)}\left[\theta_{1} \psi\left(\mathrm{p}_{1}, \mathrm{p}_{2}, \mathrm{p}_{\mathrm{P}}, \mathrm{p}_{\mathrm{T}}, \operatorname{sign}(\mathrm{u})\right) \mathrm{u}-2 \theta_{2} \mathrm{v}\right]-\theta_{3} \mathrm{a}-\mathrm{d}(\mathrm{t}) . \\
& \begin{aligned}
\psi\left(\mathrm{p}_{1}, \mathrm{p}_{2}, \mathrm{p}_{\mathrm{P}}, \mathrm{p}_{\mathrm{T}}, \operatorname{sign}(\mathrm{u})\right)= & (\mathrm{c}-\mathrm{y}) \psi_{1}\left(\mathrm{p}_{1}, \mathrm{p}_{\mathrm{p}}, \mathrm{p}_{\mathrm{T}}, \operatorname{sign}(\mathrm{u})\right) \\
& +(\mathrm{c}+\mathrm{y}) \psi_{2}\left(\mathrm{p}_{2}, \mathrm{p}_{\mathrm{p}}, \mathrm{p}_{\mathrm{T}}, \operatorname{sign}(\mathrm{u})\right)
\end{aligned}
\end{aligned}
$$

Thus

$$
\begin{aligned}
\psi\left(\mathrm{p}_{1}, \mathrm{p}_{2}, \mathrm{p}_{\mathrm{P}}, \mathrm{p}_{\mathrm{T}}, \operatorname{sign}(\mathrm{u})\right)= & \mathrm{c} \psi_{1}\left(\mathrm{p}_{1}, \mathrm{p}_{\mathrm{p}}, \mathrm{p}_{\mathrm{T}}, \operatorname{sign}(\mathrm{u})\right)+\mathrm{c} \psi_{2}\left(\mathrm{p}_{2}, \mathrm{p}_{\mathrm{p}}, \mathrm{p}_{\mathrm{T}}, \operatorname{sign}(\mathrm{u})\right) \\
& -\mathrm{y} \psi_{1}\left(\mathrm{p}_{1}, \mathrm{p}_{\mathrm{p}}, \mathrm{p}_{\mathrm{T}}, \operatorname{sign}(\mathrm{u})\right)+\mathrm{y} \psi_{2}\left(\mathrm{p}_{2}, \mathrm{p}_{\mathrm{p}}, \mathrm{p}_{\mathrm{T}}, \operatorname{sign}(\mathrm{u})\right)
\end{aligned}
$$


Define the unknown parameters as $\theta_{1}=\frac{\beta \eta}{M}, \theta_{2}=\frac{V_{0} \beta}{M}, \theta_{3}=\frac{b}{M}$ and $\mathrm{d}(\mathrm{t})=\frac{\dot{\mathrm{h}}(\mathrm{t})}{\mathrm{M}}$

Before starting the controller design, some practical assumptions on the system must be made.

The first one is that all uncertain parameters are bounded such as:

$$
\theta_{\mathrm{i}} \in\left[\theta_{\mathrm{i}_{\min }}, \theta_{\mathrm{i}_{\max }}\right], i=\{1,2,3\} .
$$

Physically, all $\theta_{i}$ are positives parameters. So we assume that $\theta_{i_{\min }}>0$. The second assumption is described by the inequality $|d(t)|<H$, where $H$ is a positive constant, defined by some maximum bound on the function $\dot{h}(t)$.

The displacement $y$ satisfies this expression $-\frac{l}{2} \leq y \leq \frac{l}{2}$. So we have: $c=\frac{V_{D}}{S}+\frac{l}{2}>\frac{l}{2}$.

Remark that in spite of the simplifications already made, the system dynamics remains highly nonlinear such as the nonlinear functions $\psi_{1}\left(p_{1}, p_{P}, p_{T}, \operatorname{sign}(u)\right), \psi_{2}\left(p_{2}, p_{P}, p_{T}, \operatorname{sign}(u)\right)$ and the change of control volumes represented by $V_{1}(y)$ and $V_{2}(y)$.

Consider now the position error as: $e_{y}=y-y_{d}$.

Let a function error $\sigma(t)$ described by (11). This function, introduced in [6], includes the integral term of $e_{y}$ in order to cancel a static error :

$$
\begin{aligned}
\sigma(t) & =\left(k+\frac{d}{d t}\right)^{3} \int_{0}^{t} e_{y}(\tau) d \tau \\
& =k^{3} \int_{0}^{t} e_{y}(\tau) d \tau+3 k^{2} e_{y}+3 k e_{v}+e_{a} .
\end{aligned}
$$

Where $e_{v}, e_{a}$ are respectively a velocity and an acceleration error. A Hurwitz polynomial can be associated to the function $\sigma(t)$, if the parameter $k$ is chosen 
as a positive one. Then the time derivative of $\sigma(t)$ along the trajectories system is given by:

$$
\begin{aligned}
\dot{\sigma}(t) & =\dot{e}_{a}+3 k e_{a}+3 k^{2} e_{v}+k^{3} e_{y} \\
& =\dot{a}+\chi(t)
\end{aligned}
$$

With: $\chi(t)=-\dot{a}_{d}+\sum_{i=0}^{2} \varpi_{i} e_{y}^{(i)}(t)$.

Where $\varpi_{0}=k^{3}, \varpi_{1}=3 k^{2}, \varpi_{2}=3 k$.

Basing on the Lyapunov approach, both a control law and an update mechanism is constructed in order to guarantee that the derivative of a suitable Lyapunov candidate function is non-positive. With the chosen function er$\operatorname{ror} \sigma(t)$, a controller designer with a Lyapunov theory is easily applied. This is justified by the relative degree of $\sigma(t)$ with respect to the tracking errors, which it equal to one. Otherwise, the recursive design procedure must be used [12], [16] and [17].

Let $\hat{\theta}_{i}$ the estimates of the parameters $\theta_{i}$ and denote $\tilde{\theta}_{i}$ the errors of parameters estimations defined by $\tilde{\theta}_{i}=\theta_{i}-\hat{\theta}_{i}$, for each $i=\{1,2,3\}$.

The integral-type update law is generally defined by some function which incorporate a tracking error and the estimated parameters. Indeed, the adaptive law can be written by $\dot{\hat{\theta}}_{i}=\tau_{i}\left(X, \hat{\theta}_{i}\right)$. So the aim consists to select a control input $u$ which can be expressed by $u=\varphi\left(X, \hat{\theta}_{i}\right)$ and the adaptation functions $\tau_{i}$ to ensure a global stability of the whole system. To achieve the required purpose, a Lyapunov function candidate $V\left(X, \tilde{\theta}_{i}\right)$ is defined. This function is described by a quadratic term in the parameter estimation errors and the tracking error, which is given by:

$$
V=\frac{1}{2} \sigma^{2}(t)+\frac{1}{2} \sum_{i=1}^{3} \tilde{\theta}_{i}^{T} \Gamma^{-1} \tilde{\theta}_{i}
$$

$\Gamma \in \mathbb{R}^{(3 \times 3)}$ is a positive symmetric matrix.

The time derivative of the defined Lyapunov function $V$ along the system trajectories is obtained as: 


$$
\begin{aligned}
\dot{V}= & \sigma \dot{\sigma}(t)-\sum_{i=1}^{3} \tilde{\theta}_{i}^{T} \Gamma^{-1} \dot{\hat{\theta}}_{i}, \\
= & \sigma\left[\frac{1}{\left(c^{2}-y^{2}\right)}\left(\theta_{1} \psi\left(p_{1}, p_{2}, p_{P}, p_{T}, \operatorname{sign}(u)\right) u-2 \theta_{2} v\right)-\theta_{3} a-d(t)+\chi\right] \\
& -\sum_{i=1}^{3} \tilde{\theta}_{i}^{T} \Gamma^{-1} \dot{\hat{\theta}}_{i} .
\end{aligned}
$$

In order to design a controller and adaptation laws, it is sufficient to replace $\theta_{i}$ by $\hat{\theta}_{i}+\tilde{\theta}_{i}$, in the equation (15). Then the control law can be structured as:

$$
u=\frac{\left(c^{2}-y^{2}\right)}{\hat{\theta}_{1} \psi\left(p_{1}, p_{2}, p_{P}, p_{T}, \operatorname{sign}(u)\right)}\left[u_{1}+u_{2}+u_{3}\right] .
$$

Where $u_{1}=-\chi$ is the controller part which allows the compensation of certain known components, $u_{2}=\frac{2 \hat{\theta}_{2} v}{\left(c^{2}-y^{2}\right)}+\hat{\theta}_{3} a$ is an adaptive part used to overcome the problem from uncertain parameters, $u_{3}$ is a robust part of controller defined in order to compensate the function $d(t)$ related to the poorly modelled dynamics of dry friction. Indeed, the robust controller is designed by $u_{3}=-k_{1} \sigma-\frac{H}{\varepsilon}$. This choice is explained below. $k_{1}, H$ and $\varepsilon$ are positive constants.

It is clear that the singularity of the equation (15) happens when $\psi\left(p_{1}, p_{2}, p_{P}, p_{T}, \operatorname{sign}(u)\right)=0$, which can be occur when the pressure in the two chambers are equal respectively to the supply and the exhaust pressure. Or according to the assumption (5), this problem is avoided.

$$
\begin{aligned}
& \text { Substituting (15) into (14) } \dot{V} \text { becomes: } \\
& \begin{aligned}
\dot{V} & =-k_{1} \sigma^{2}-\tilde{\theta}_{1} \frac{\psi\left(p_{1}, p_{2}, p_{P}, p_{T}, \operatorname{sign}(u)\right)}{\left(c^{2}-y^{2}\right)} \sigma u-\frac{2 v}{\left(c^{2}-y^{2}\right)} \tilde{\theta}_{2} \sigma \\
& -\tilde{\theta}_{3} a \sigma-\sigma d(t)-\frac{H}{\varepsilon} \sigma-\sum_{i=1}^{3} \tilde{\theta}_{i}^{T} \Gamma^{-1} \dot{\hat{\theta}}_{i}
\end{aligned}
\end{aligned}
$$

To make sure that $\dot{V}$ is semi-definite negative, the adaptation laws can be chosen as: 


$$
\left\{\begin{array}{l}
\dot{\hat{\theta}}_{1}=\tau_{1}=\Gamma_{11} \sigma \frac{\psi\left(p_{1}, p_{2}, p_{P}, p_{T}, \operatorname{sign}(u)\right)}{\left(c^{2}-y^{2}\right)} u, \\
\dot{\hat{\theta}}_{2}=\tau_{2}=-\Gamma_{22} \frac{2 v}{\left(c^{2}-y^{2}\right)} \sigma \\
\dot{\hat{\theta}}_{3}=\tau_{3}=-\Gamma_{33} \sigma a .
\end{array},\right.
$$

Where $\Gamma_{11}, \Gamma_{22}, \Gamma_{33}$ are the components of the matrix $\Gamma$.

With the knowledge of the set values of estimated parameters, it is interesting to use this information for the adaptation mechanism designer. Indeed, the knowledge of $\theta_{i_{\min }}$ and $\theta_{i_{\max }}$ for each parameters helps to speed up the convergence of adaptive mechanism, reduce the transition effect and prevent $\hat{\theta}_{1}$ from tacking the value zero.

For meeting this requirement, a simple modification is introduced at the equations of adaptation law (18):

$$
\dot{\hat{\theta}}_{\mathrm{i}}=\operatorname{Proj}\left\{\tau_{\mathrm{i}}\right\}, \mathrm{i}=\{1,2,3\} .
$$

So this modification is just described by the discontinuous projection [11]:

$$
\operatorname{Proj}\left(\tau_{\mathrm{i}}\right)=\left\{\begin{array}{l}
0 \text { if } \hat{\theta}_{\mathrm{i}}=\theta_{\mathrm{i}_{\max }} \text { and } \tau_{\mathrm{i}}>0, \\
0 \text { if } \hat{\theta}_{\mathrm{i}}=\theta_{\mathrm{i}_{\min }} \\
\tau_{\mathrm{i}} \text { Otherwice. }
\end{array} \text { and } \tau_{\mathrm{i}}<0,\right.
$$

The projection method presented in [18] guarantees the condition (10) and always holds the following equation $\tilde{\theta}_{i}^{T}\left(\Gamma^{-1} \operatorname{Pr} \operatorname{oj}\left(\tau_{i}\right)-\tau_{i}\right) \leq 0$.

Thus, from the system (18) the system (17) can be rewritten as:

$$
\dot{\hat{\theta}}_{\mathrm{i}}=\operatorname{Proj}\left\{\Gamma \sigma\left[\frac{\psi\left(\mathrm{p}_{1}, \mathrm{p}_{2}, \mathrm{p}_{\mathrm{P}}, \mathrm{p}_{\mathrm{T}}, \operatorname{sign}(\mathrm{u})\right)}{\left(\mathrm{c}^{2}-\mathrm{y}^{2}\right)} \mathrm{u},-\frac{2 \mathrm{v}}{\left(\mathrm{c}^{2}-\mathrm{y}^{2}\right)},-\mathrm{a}\right]^{\mathrm{T}}\right\} .
$$

Substituting the adaptation laws defined by (19) into the equation (16):

$$
\dot{V} \leq-k_{1} \sigma^{2}-\sigma \cdot d(t)-\frac{H}{\varepsilon} \sigma .
$$


In order to ensure the non-positiveness of $\dot{V}$, we must impose some positive bound value $\varepsilon$ on $\sigma$, which is chosen arbitrarily. The proof is done by the contraposition.

Supposed that $|\sigma| \geq \varepsilon$ and we know that $|d(t)| \leq H$, so in this sense two cases can be presented. If $\sigma \geq \mathcal{E}$ and $d(t) \geq-H$ the following equation can be written:

$$
\begin{gathered}
\frac{\sigma^{2}}{\varepsilon} \geq \sigma \Rightarrow \frac{H \sigma^{2}}{\varepsilon} \geq H \sigma, \\
H \sigma \geq-\sigma d(t) .
\end{gathered}
$$

With both equations (21) and (22), the following inequality is checked:

$$
\sigma . d(t)+\frac{H}{\varepsilon} \sigma \geq 0 .
$$

In the same manner, the equation (23) is obtained for $\sigma \leq-\varepsilon$ and $d(t) \leq H$.

Then, we have $\dot{V} \leq 0$ which implies that $|\sigma| \leq \varepsilon$ and the parameter estimation errors remain bounded and also can be made arbitrarily small.

Based on the work done in [20], the function $\delta(t)=e_{y}(t) e^{k t}$ can be defined. So we can obtain:

$$
\dddot{\delta}(t)=\dot{\sigma}(t) e^{k t} .
$$

Integrating (24), the following equation holds:

$$
\ddot{\delta}(t)-\ddot{\delta}(0)=\sigma(t) e^{k t}-\sigma(0)-k \int_{0}^{t} \sigma(\tau) e^{k \tau} d \tau .
$$

Then we can write,

$$
|\ddot{\delta}(t)-\ddot{\delta}(0)+\sigma(0)| \leq|\sigma(t)| e^{k t}+k \int_{0}^{t}|\sigma(\tau)| e^{k \tau} d \tau .
$$

And we have $|\sigma(t)| \leq \varepsilon$.

Then,

$$
\left\{\begin{array}{l}
\dddot{\delta}(t) \leq 2 \varepsilon e^{k t}+\xi_{1}, \\
\dddot{\delta}(t) \geq-2 \varepsilon e^{k t}+\xi_{1}^{\prime}
\end{array}\right.
$$

Where

$$
\left\{\begin{array}{l}
\xi_{1}=\ddot{\delta}(0)-\sigma(0)-\varepsilon, \\
\xi_{1}^{\prime}=\ddot{\delta}(0)-\sigma(0)+\varepsilon .
\end{array}\right.
$$

Integrate the first equation of system (25) at three times, so these following inequalities are: 


$$
\begin{aligned}
\delta(t) & \leq \frac{2 \varepsilon}{k^{2}} e^{k t}+\left(\xi_{1} t^{2}+\xi_{2} t+\xi_{3}\right) \\
& \Rightarrow e_{y}(t) \leq \frac{2 \varepsilon}{k^{2}}+\left(\xi_{1} t^{2}+\xi_{2} t+\xi_{3}\right) e^{-k t}
\end{aligned}
$$

With $\xi_{2}, \xi_{3}$ are constants which include the initial condition of $\dot{\delta}(0), \delta(0)$ where :

$$
\left\{\begin{array}{l}
\xi_{2}=\dot{\delta}(0)-\frac{2 \varepsilon}{k}, \\
\xi_{3}=\delta(0)-\frac{2 \varepsilon}{k^{2}} .
\end{array}\right.
$$

Thus when time tends to infinity, the inequality (26) becomes

$$
e_{y}(t) \leq \frac{2 \varepsilon}{k^{2}} .
$$

From the second equation of system (25), we can show in the same manner the following inequality:

$$
e_{y}(t) \geq-\frac{2 \varepsilon}{k^{2}}
$$

So we can deduce that for a bounded function error, $\sigma(t)$ the absolute value of the error dynamics $e_{y}(t)$ is bounded by $\frac{2 \varepsilon}{k^{2}}$.

Finally we have that $\sigma(t)$, the tracking position error $e_{y}(t)$ and all state variables of system (6) are bounded. Moreover with the discontinuous projection included in the adaptation law, we ensure that all estimated parameters are always bounded and satisfy the equation (10). The fact that the Lyapunov function $\mathrm{V}$ is semi-negative implies:

$$
\sum_{i=1}^{3} \tilde{\theta}_{i}^{T}(t) \Gamma^{-1} \tilde{\theta}_{i}(t) \leq 2 V(t) \leq 2 V(0) .
$$

then

$$
\sum_{i=1}^{3} \tilde{\theta}_{i}^{T}(t) \Gamma^{-1} \tilde{\theta}_{i}(t) \leq \sigma^{2}(0)+\sum_{i=1}^{3} \tilde{\theta}_{i}^{T}(0) \Gamma^{-1} \tilde{\theta}_{i}(0) .
$$

This bound shows that the possibility for reducing the estimation parameters errors lies in $\sigma(0)$, that could be chosen as small as possible.

So we can conclude that the synthesized controller permit a global stability of the closed loop system with a bounded position error. 


\section{Simulation Results}

To illustrate the above controller design, a simulation results are obtained for a hydraulic cylinder. The control model of system and the controller design are both developed on the Simulink software. The sampling frequency of the control loop is equal to $1 \mathrm{Khz}$.

The value of position tracking error is related to controller parameter $k$ and $\varepsilon$, with the last one can be chosen arbitrarily. As the placement of poles, the value of the gain $k$ can be computed taking into account the natural frequency of the tangent linearized model for the central position. This pulsation is about $1000(\mathrm{rad} / \mathrm{s})$. So we can impose the closed-loop dynamics system by acting on the gain $k$. For example, we can choose the value of $k$ in order to obtain the closed-loop system twice faster than the open-loop one. On the other hand, when $k$ is so high, the performance of the control system and the update laws will be affected by some chattering phenomenon. Therefore, it is important to select an appropriate $k$.

Note that the stability and convergence of the RAC is guaranteed for any positive $\Gamma_{11}, \Gamma_{22}, \Gamma_{33}$. However, the performance of the controller will depend critically on these gains. If small gains are chosen the adaptation will be slow and the transient tracking error will be large. Conversely, when the magnitudes of the gains are too large will lead to very oscillatory parameters. Therefore, the choice of these parameters is a difficult task.

The desired trajectory is a sinusoidal curve given by $y_{d}(t)=0.01 \sin (10 t)$. The true system parameters that are used in the control model are set as follows: $b=400\left[\mathrm{~N} / \mathrm{m} . \mathrm{s}^{-1}\right], \beta=17000[$ bars $]$ and $\eta=2.545 * 10^{-7}[\mathrm{Kg} /$ s.Pascal.V $]$.

A direct validation is carried out to the control model. It consists in comparing respectively the actual position, velocity and acceleration to their desired one (Fig.3, Fig.5, Fig.7). These figures show the effectiveness of the control schema. Figures 4, 6 and 8 illustrate that the errors of position, of velocity and of acceleration are very small. 


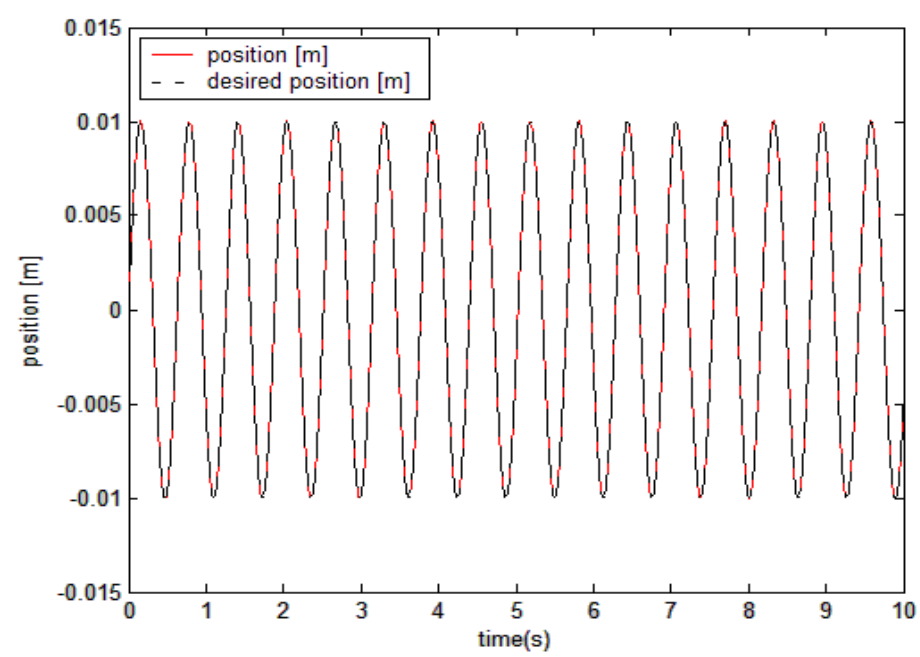

Fig. 3. Position and desired position

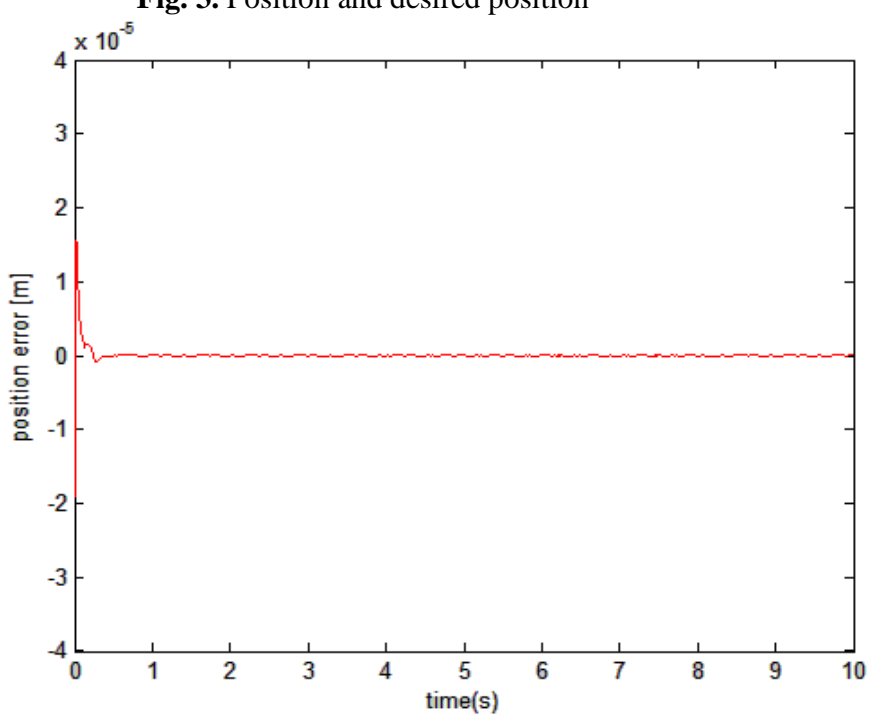

Fig. 4. Error position 


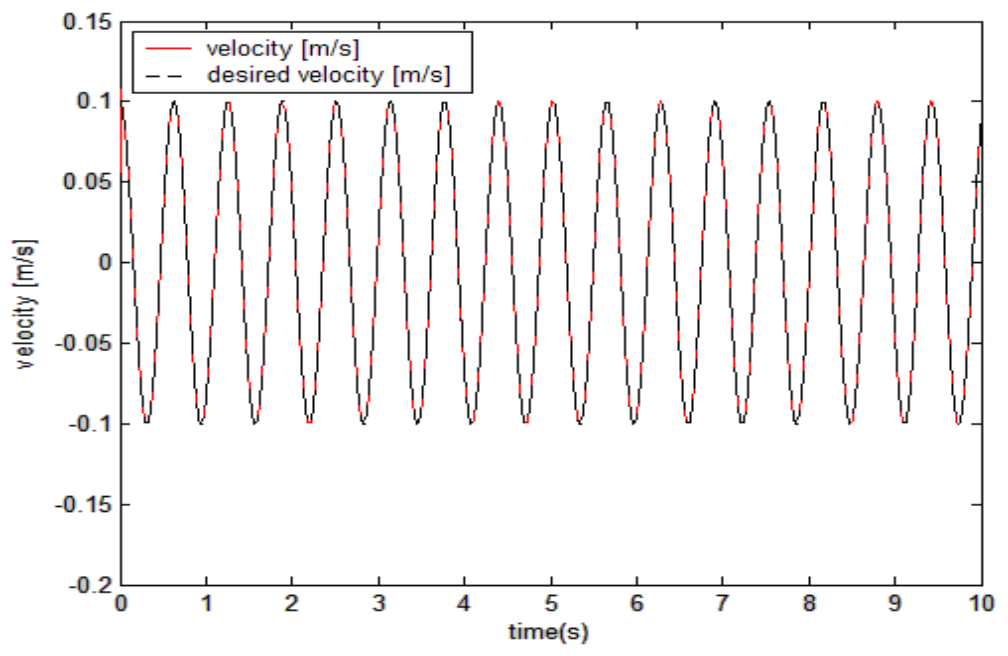

Fig. 5. Velocity and desired velocity

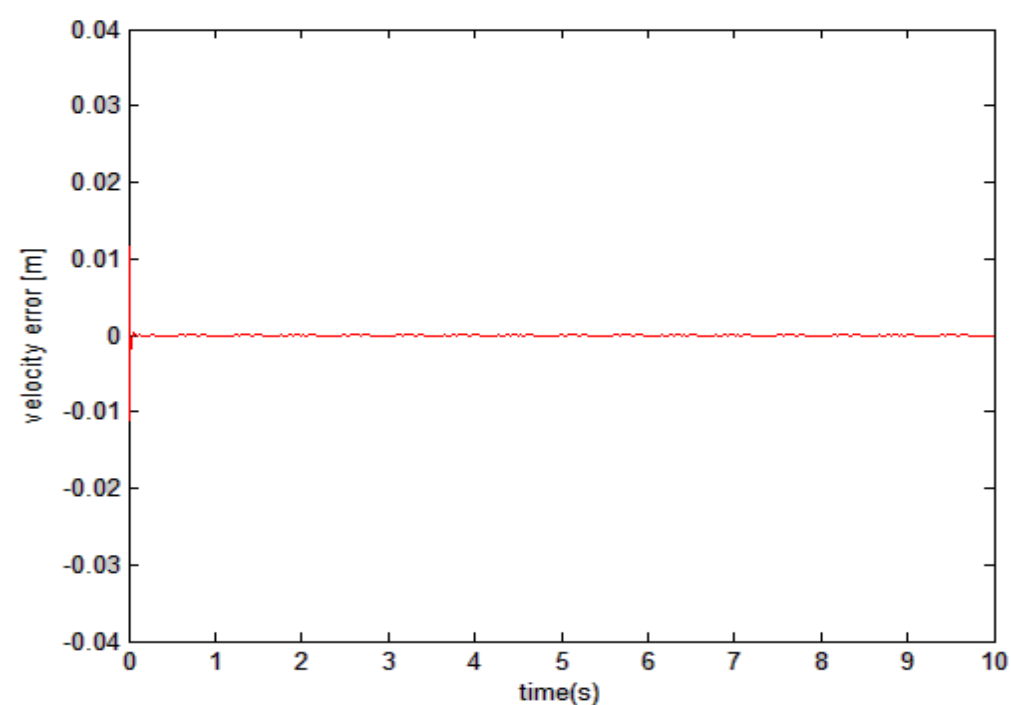

Fig. 6. Error velocity 


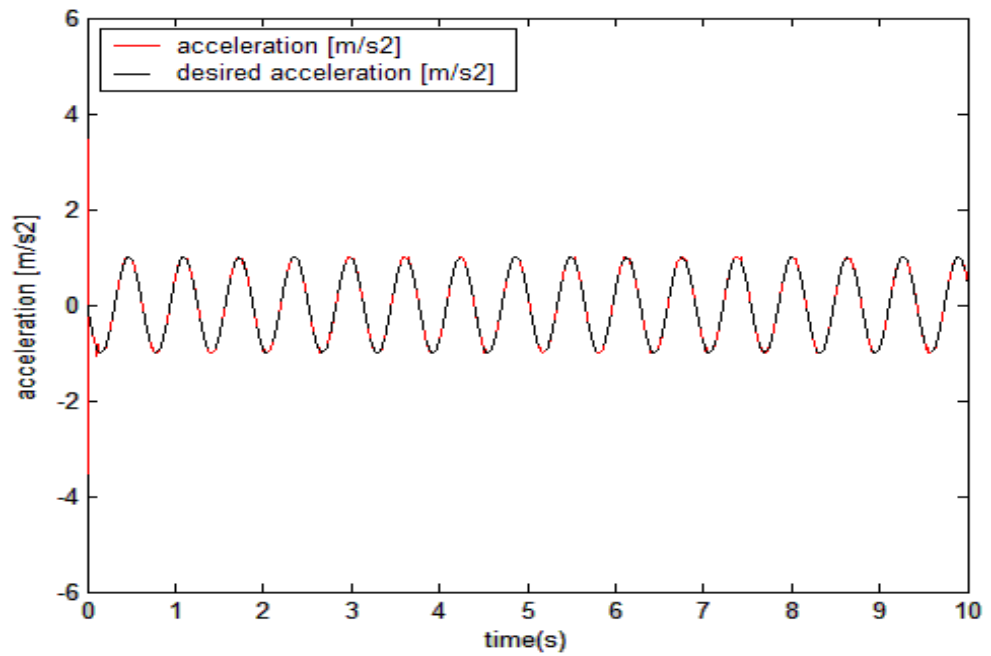

Fig.7. Acceleration and desired acceleration

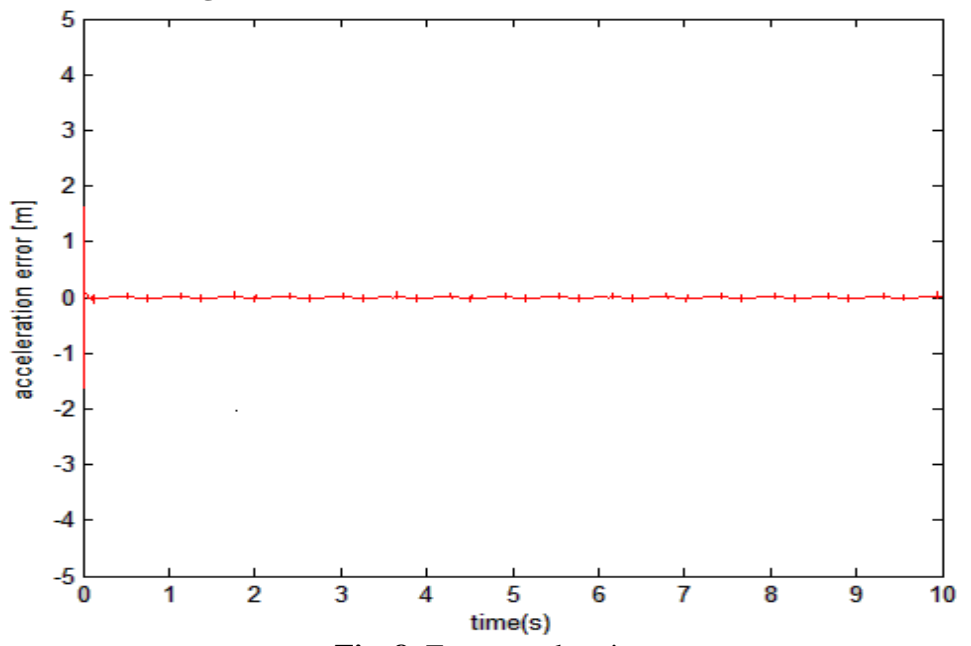

Fig. 8. Error acceleration

Figures 9,10 and 11 shows the evolution and the convergence of the dynamic parameters along the tracking trajectory and the control law is presented in Fig.12. 


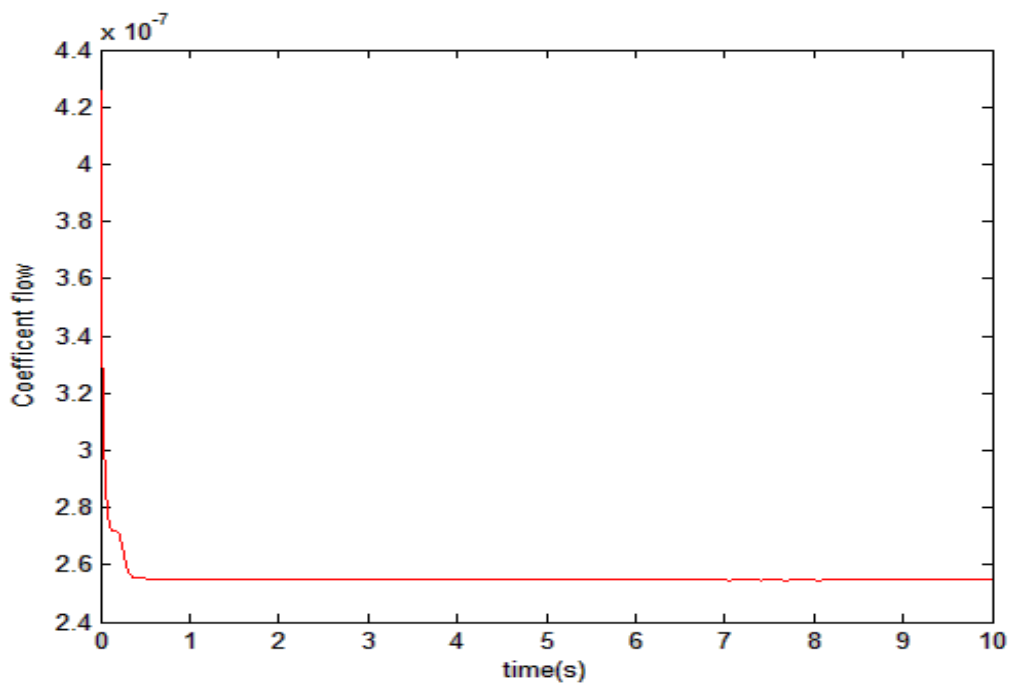

Fig. 9. Evolution of parameter $\hat{\eta}$

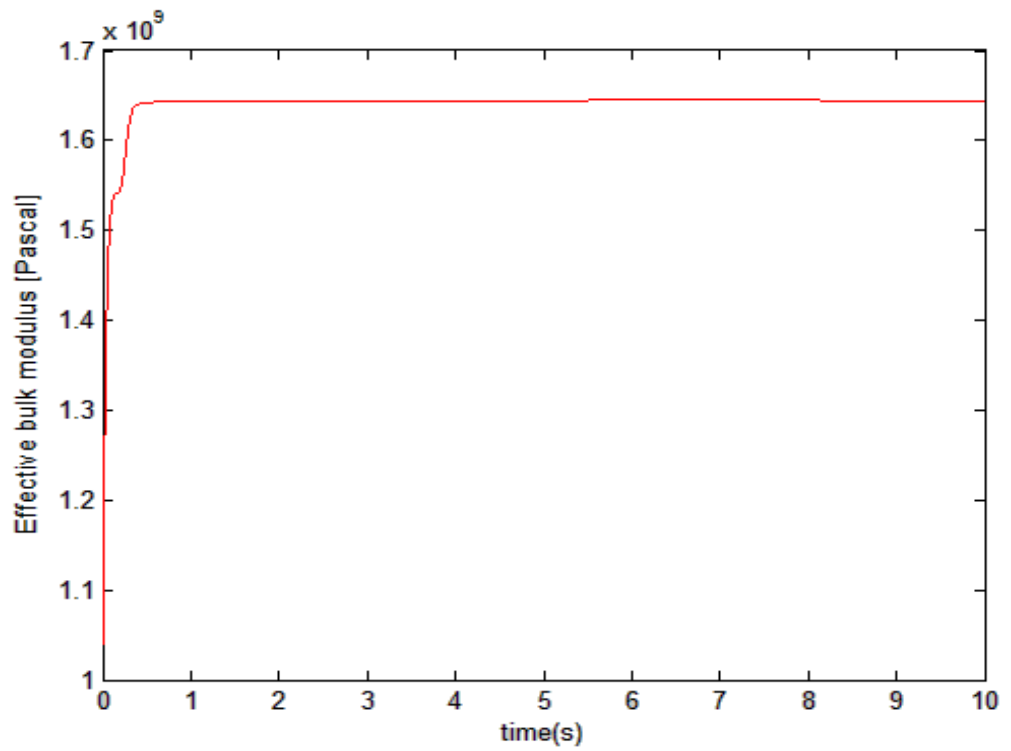

Fig. 10. Evolution of parameter $\hat{\beta}$ 


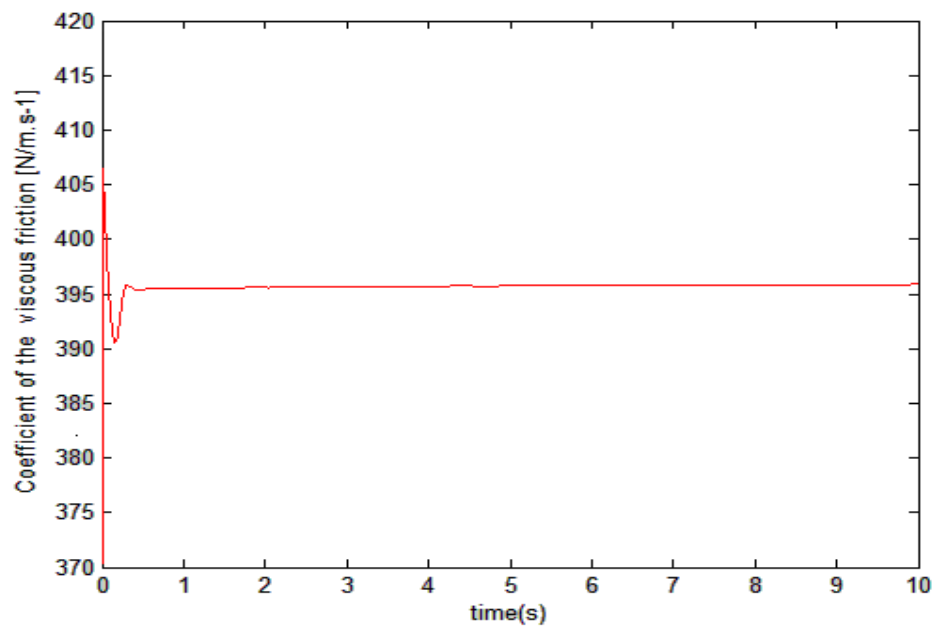

Fig. 11. Evolution of parameter $\hat{b}$

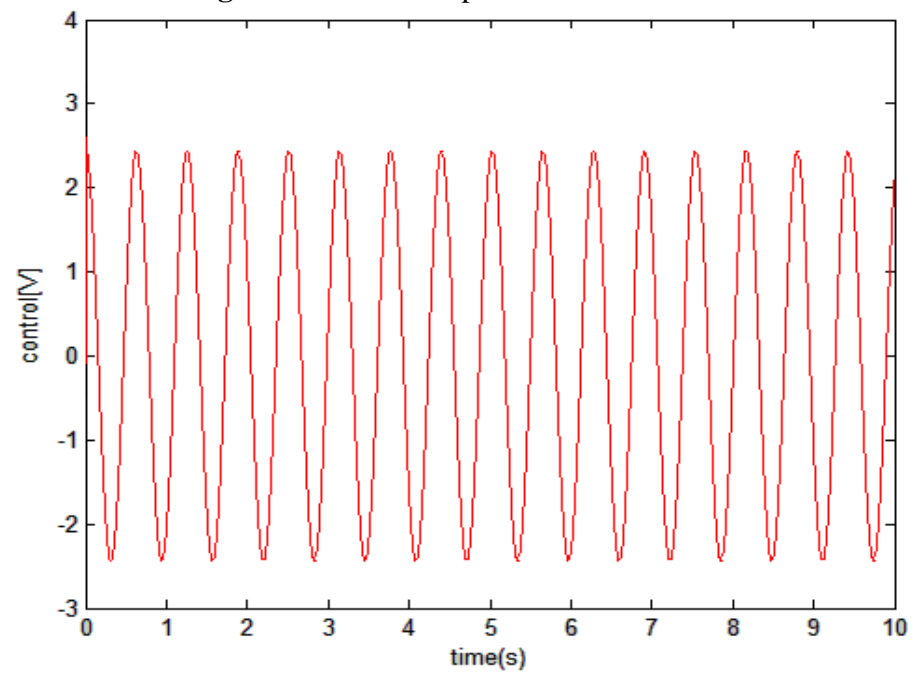

Fig. 12. Control law

The identified parameters correspond to the a priori values of the model system with small relative standard deviations which can due to the features of the reference signals.

With appropriate chosen of adaptation gains, the parameter convergence has the smallest transient tracking error. 


\section{Conclusion and perspectives}

In this work, an RAC controller based on discontinuous projection method is applied for the high performance robust motion control of a special electrohydraulic servo-system. The controller which is based on the Lyapunov theory takes into account the particular nonlinearities associated with hydraulic dynamics and allows parametric uncertainties as well as uncertain nonlinearities coming from uncompensated friction dry forces. Simulation results show that the proposed scheme achieves a better tracking performance. The basic idea in this application of this controller is especially to estimate on-line the coefficient of flow gain, based on the measured system signals and using the estimated parameters in the control input computation.

From this study we can consider several future works. One is to show the effectiveness of the presented controller on the simulation model already presented and also on the test bench. Another is the consideration of the partial measured of the state. So in this case, the study of an estimator is required. The third one consists to replace the actually robust method by a sliding integral smoothing technique.

\section{References}

Alleyne A. and Hedrick J. K., (1995). Nonlinear adaptive control of active suspensions, IEEE Trans. Control Syst. Technol., 1: 94-101, Mars. doi: 10.1109/87.370714.

Bobrow J. E. and Lum K., (1996), Adaptive, high bandwidth control of a hydraulic actuator, ASME J. Dynam. Syst., Meas., Contr.,4: 714-720, doi: 10.1115/1.2802347.

Bonchis A., Corke P. I., Rye D. C. and Ha Q. P., (2001), Variable structure methods in hydraulic servo systems control, Automatica, 37, 589-595. doi: 10.1016/S0005-1098(00)00192-8.

Bu F. and Yao B., (2001), Integrated Direct/lndirect Adaptive Robust Motion Control of Single-Rod Hydraulic Actuators with Time-Varying Unknown Inertia, IEEE/ASME International Conference on Advanced Intelligent Mechatronics Proceedings, Como,Italy.

Bouri M. and. Thomasset D, ( 2001), Sliding Control of an Electropneumatic Actuator Using an Integral Switching Surface, IEEE Transaction On Control Systems Technology, 9-2, doi: 10.1109/87.911388.

Guan C. and Pan S., Adaptive sliding mode control of electro-hydraulic system with nonlinear unknown parameters, (2008), Control Engineering Practice, 11: 1275-1284 doi: 10.1016/j.conengprac.2008.02.002.

Guan C. and Pan S., (2008), Nonlinear Adaptive Robust Control of Single-Rod Electro-Hydraulic Actuator With Unknown Nonlinear Parameters, IEEE Transactions On Control Systems Technology, 16,. doi: 10.1109/TCST.2007.908195. 
Hisseine D., ( 2005), Robust tracking control for a hydraulic actuation system, IEEE conference on control applications, 422-427.

Isidori A. , (1989), Nonlinear Control Systems Design, Springer, 479.

Krstiçacute M., kanellakopoulos L. and Kokotoviçcute P., (1995), Nonlinear and Adaptive Control Design, John Wiley\&Sons, Inc., 563.

Merritt H. E., (1967), Hydraulic control systems, New York: Wiley, 368.

Li D. and. Salcuden S. E, (1997), Modeling, simulation, and control of a hydraulic stewart platform, IEEE Int. Conf. Robot. Autom., 3360-3366.

Liu Y., and Handroos H., (1999), Technical note sliding mode control for a class of hydraulic position servo, Mechatronics, 1: 111-123.

Slotine J.E. and Li W., (1991), Applied Nonlinear Control, Prentice-Hall, 461.

Plummer A. R. and Vaughan N. D. , (1996), Robust adaptive control for hydraulic servosystems, ASME J. Dynamic System, Measurement and Control, 118: 237-244. doi: 10.1115/1.2802309.

Re L. D. and Isidori A., (1995), Performance enhancement of nonlinear drives by feedback linearization of linear-bilinear cascade models, IEEE Trans. Control Syst. Technol. ,2: 299-308, doi: 10.1109/87.406977.

Yao B., Bu F., and Chiu G. T. C., (1998), Nonlinear adaptive robust control of electro-hydraulic servo systems with discontinuous projections, IEEE Conf. Decision Control, 2265-2270.

Yao B., Bu F., Reedy J., and Chiu G.T.C., (2000), Adaptive Robust Motion Control of Single-Rod Hydraulic Actuators: Theory and Experiments, IEEE/ASME Transactions On Mechatronics.5- 1, doi: 10.1109/3516.828592.

Yao B., Bu F. and. Chiu G. T. C, (2001), Non-linear adaptive robust control of electro-hydraulic systems driven by double-rod actuators". Int. J. Control, 8: 761775, doi: 10.1080/002071700110037515.

Yao B., and Tomizuka M., (1997), Adaptive robust control of SISO nonlinear systems in a semi-strict feedback form, Automatica, 33: 893-900. doi: 10.1016/S0005-1098(96)00222-1.

Yu C., H.Xu, Y.Liu and S.Huang,, (2006), Sliding mode control based on fuzzy neural network for missile electro-hydraulic servo mechanism, 13th International Conference On Neural Information Processing, 596-604 . 